\title{
PENGEMBANGAN LKS MATEMATIKA DENGAN PENDEKATAN SAINTIFIK POKOK BAHASAN POLINOMIAL UNTUK SMA KELAS XI
}

\author{
${ }^{1}$ Zara Anisa Islami Arifin, ${ }^{2}$ Dzikriyah Nur Aliyah Sepriyani \\ ${ }^{1}$ Universitas PGRI Yogyakarta, Asrama Kompi Kavaleri 2 JRTR Demak Ijo, Gamping, Sleman, 085226159499 \\ ${ }^{2}$ Universitas PGRI Yogyakarta, Kauman Temanggung Jawa Tengah, 085643077238 \\ e-mail: zaraanisa1797@gmail.com
}

\begin{abstract}
Abstrak
Salah satu bahan ajar yang dapat dikembangkan untuk membuat pembelajaran menjadi aktif dan bermakna adalah menggunakan Lembar Kegiatan Siswa. Lembar kegatan siswa disusun agar dapat membantu siswa dalam membangun konsep dan mengembangkannya. Penelitian ini bertujuan untuk mengembangkan dengan pendekatan santifik pada pokok bahasan polinom. Metode yang digunakan dalam penelitian dan pengembangan yaitu research and Development. Dari hasil penelitian guru dan siswa terhadap lembar kegiatan siswa berbasis pendekatan saintifik pada pokok bahasan polinom, diperoleh persentase pada aspek kesesuaian isi 80,7\%, keterbacaan $83,2 \%$, dan konstruksi $82,4 \%$, yang semuanya dapat dikategorikan sangat tinggi. Hasil tanggapan siswa terhadapa kemenarikan yakni $73,5 \%$, dan keterbacaan $86,3 \%$, dapat dikategorikan sangat tinggi.
\end{abstract}

Kata Kunci: Lembar Kegiatan Siswa, Pendekatan Saintifik, Polinom

\begin{abstract}
One of the teaching materials that can be developed to make learning active and meaningful is to use the Student Activity Sheet. Sheets of student entrapment are structured to assist students in building concepts and developing them. This study aims to develop with a santifik approach on the subject of the polynomial. The method used in research and development is research and development. From the result of the research of the teacher and the student to the student activity sheet based on the scientific approach on the subject of polynomial, the percentage of content conformity is $80,7 \%$, the readability $83,2 \%$, and the construction $82,4 \%$, all of which can be categorized as very high. The result of the student's responses to the attractiveness of $73.5 \%$, and the readability of $86.3 \%$, can be categorized as very high.
\end{abstract}

Keywords: Student Activity Sheet, Scientific Approach, Polynomial

\section{PENDAHULUAN}

Matematika merupakan mata pelajaran yang diajarkan mulai dari sekolah dasar (SD) hingga jenjang perguruan tinggi. Pembelajaran matematika juga merupakan bagian dari ilmu dasar yang bertujuan untuk membekali siswa agar berpikir logis, analitis, sistematis, kritis dan kreatif serta kemampuan kerjasama (Risnawati, 2008:11). Namun pada kenyataanya pembelajaran yang diterapkan oleh guru disekolahan kurang berjalan dengan efisien, karena kebanyakan dari siswa hanya mengenal matematika melalui rumus yang dijelaskan oleh guru tanpa mengenal masalah yang terdapat dalam kehidupan sehari-hari. Hal ini terjadi karena siswa belum memahami dengan benar apa itu tentang matematika.

Kurikulum yang digunakan pada pendidikan saat ini adalah kurikulum 2013. Kurikulum 2013 mengajarkan siswa belajar secara mandiri dalam menemukan atau mengenal konsep 
materi pembelajaran dan menitik beratkan siswa pada tiga aspek penilaian yaitu pada pengetahuan, sikap, dan keterampilan.

Kegiatan pembelajaran matematika dikatakan berhasil jika hasil belaajr siswa mencapai hasil yang optimal. Untuk mendapatkan hasil yang optimal harus didukung dari komponen pembelajaran salah satu komponen pembelajaran tersebut adalah bahan ajar, bahan ajar digunakan oleh guru. Bahan ajar adalah seperangkat materi pembelajaran yang disusun secara sitematik, yang digunakan oleh guru dan peserta didik dalam proses pembelajaran yang berlangsung. Contoh dari bahan ajar berupa buku, LKS, dan modul yang digunakan oleh siswa atau pun oleh guru. (Ardiani dalam Andi 2011:16).

Salah satu materi pembelajaran matematika adalah polynomial. Materi ini juga diguanakan dalam kehidupan sehari-hari. Meteri polynomial ini dipelajari di tingkat SMA kelas XI. Meskipun materi ini sangat penting untuk kehidupan sehari-hari tetapi siswa masih menghafalkan rumus sehingga sulit untuk siswa memahami dengan benar materi polynomial tersebut dan kesulitan dalam pengerjaan soal yang berhubungan dengan materi polynomial. Karena masih banyaknya siswa yang cenderung menghafalkan rumus dan tidak memahami konsep dengan baik dan benar. Padahal mengerjakan soal matematika akan lebih mudah jika mengetahui konsep matematika pada materi tersebut karena siswa akan memahami permasalahan pada soal sehingga siswa mengerti apa yang harus mereka lakukan untuk menyelesaikan permasalahan tersebut.

Oleh karena itu agar siswa lebih mudah memahami konsep matematika guru harus menggunakan bahan ajar dan metode pembelajaran yang dapat memudahkan siswa dalam memahami konsep matematika dengan pemahamannya sendiri. Salah satu pendekatan pembelajaran yang menerapkan teori konstruksivisme adalah pendekatan saintifik. Para ahli meyakini bahwa dengan pendekatan saintifik ini siswa akan lebih aktif mengonstruk pengetahuan dan keterampilannya, selain itu juga dapat mendorong siswa untuk melakukan penyelidikan guna menemukan fakta-fakta dari suatu fenomena atau kejadian (Bintari dkk, 2014).

Salah satu bahan ajar yang digunakan oleh guru agar menciptakan proses pembelajaran yang dapat mengembangkan siswa dalam memahami konsep matematika adalah menggunakan Lembar Kegiatan Siswa (LKS). LKS merupakan salah satu bahan ajar cetak berupa lembaran berisi materi, ringkasan dan petunjuk-petunjuk pelaksanaan tugas pembelajaran yang harus dikerjakan oleh peserta didik, yang mengacu kepada kompetensi dasar yang harus dicapai. Diharapkan dengan digunakannya LKS, siswa dapat menemukan konsep pembelajaran 
matematika dalam pemecahan masalah sehari-hari. Oleh karena itu sebaiknya dalam langkahlangkah pembelajaran menggunakan LKS memuat materi yang terstruktur, ringkasan dan tugas yang berkaitan antara materi pembelajaran dengan kehidupan sehari-hari.

\section{METODE PENELITIAN}

Metode yang digunakan dalam penenlitian ini adalah $\mathrm{R} \& \mathrm{D}$ (Research and Development). Untuk subyek yang digunakan untuk penelitian adalah siswa MAN 1 Sleman yang terdiri 20 siswa kelas XI jurusan IPA. LKS yang telah dikembangkan sebagai alat penelitian. Prosedur penilaian diadaptasi dari prosedur pengembangan Sugiyono (sugiyono,2017: 409)

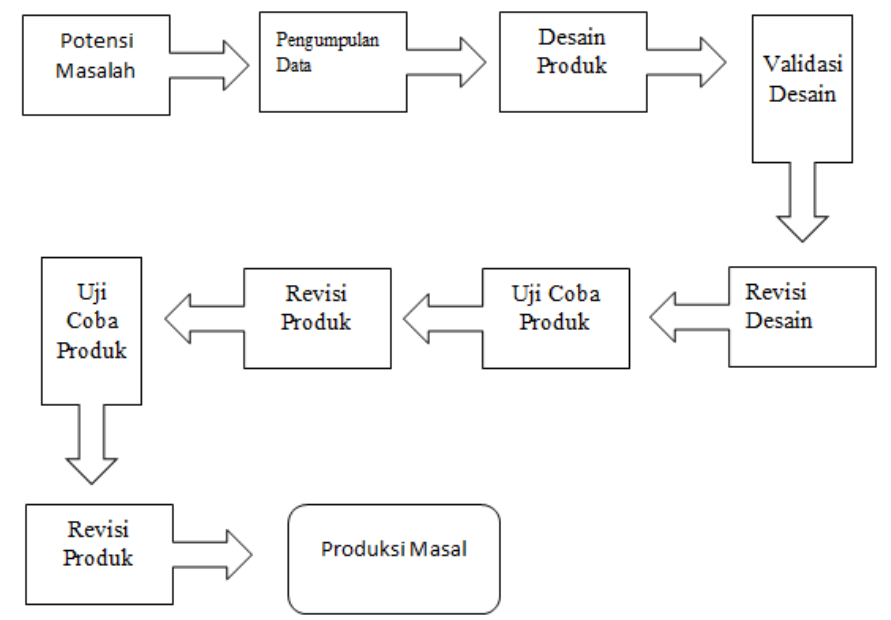

Gambar 1. Prosedur Penilaian

Sedangkan untuk instrumen penelitian yaitu:

1. Lembar Observasi

Lembar observasi dibuat berdasarkan langkah-langkah pembelajaran kooperatif tipe Numbered Heads Together (NHT). Lembar observasi bertujuan untuk mengamati tigkah laku guru secara langsung saat pembelajaran didalam kelas. Bentuk lembar observasi yang digunakan adalah ceklis.

2. Angket Respon

Lembar angket respon siswa dibuat untuk memperoleh data mengenai respon siswa pada pembelajaran matematika.

3. Angket Pakar Ahli

Lembar angket pakar ahli dibuat untuk memvalidasi modul yang akan dikembangkan 
Kegiatan untuk teknik analisis data kesesuaian isi, keterbacaan konstruksi, dan kemenarikan LKS dengan pendekatan sai tifik, yang meliputi

1. Mengklarifikasi dan mengkode data

2. Melakukan tabulasi data berdasarkan klarifikasi data

3. Memberikan skor jawaban responden. Penskoran meliputi kesesuaian isi, keterbacaan konstruksi dan kemenarikan LKS

4. Mengolah jumlah skor responden. Jawaban angket adalah:

a. Skor untuk pernyataan sangat setuju (SS), skor $=4 \mathrm{x}$ jumlah jawaban responden

b. Skor untuk pernyataan setuju (S), skor $=3 \times$ jumlah jawaban responden

c. Skor untuk pernyataan tidak setuju (TS), skor $=2 \mathrm{x}$ jumlah jawaban responden

d. Skor untuk pernyataan sangat tidak setuju (STS), skor $=1 \mathrm{x}$ jumlah jawaban responden

Tabel 1. Retting Scale

\begin{tabular}{lc}
\hline \multicolumn{1}{c}{ Pilihan Jawaban } & Skor \\
\hline Sangat Setuju (SS) & 4 \\
Setuju (S) & 3 \\
Tidak Setuju (TS) & 2 \\
Sangat Tidak Setuju (STS) & 1 \\
\hline
\end{tabular}

e. Menghitung presentasi jawaban responden setiap pernyataan dengan menggunakan rumus

$\% X_{\text {in }}=\frac{\sum s}{S_{\text {maks }}} \times 100 \%$

(Sujana, 2005)

Keterangan:

$\% X_{\text {in }}=$ Persentase skor jawaban pernyataan pada angket LKS

$\sum s=$ Jumlah skor jawaban total

$S_{\text {maks }}=$ Skor maksimum yang diharapkan

f. Menafsirkan persentase skor jawaban setiap pernyataan dan rata-rata persentase angket menurut Arikunto (Arikunto, 2015), seperti yang tertera pada tabel 2

Tabel 2. Tafsiran Skor

\begin{tabular}{lc}
\hline \multicolumn{1}{c}{ Persentase } & Kriteria \\
\hline $80,1 \%-100 \%$ & Sangat Tinggi \\
$60,1 \%-80 \%$ & Tinggi \\
$40,1 \%-60 \%$ & Sedang \\
$20,1 \%-40 \%$ & Rendah \\
$0,0 \%-20 \%$ & Sangat rendah \\
\hline
\end{tabular}

Prima, Vol. 3, No. 1, Januari 2019, 9-15. 


\section{HASIL DAN PEMBAHASAN}

Pada tahap ini pada studi kurikulum menganalisis KI dan KD, Indikator, tujuan pembelajaran, serta analisis konsep. Hasil dari pengembangan Lembar Kegiatan Siswa (LKS) yaitu LKS yang memuat halaman identitas (judul LKS), halaman orientasi (memuat kompetensi dasar, indikator, dan tujuan pembelajaran) pada lampiran pertama. LKS utama (memuat empat soal yang terdiri dari 3 soal masalah konstektual, 1 soal analisis dengan pendekatan saintifik). Pada LKS utama siswa akan membangun konsep mengenai: (1) pada soal nomer 1, menentukan nilai dari suatu suku banyak, (2) pada soal 2, mencari nilai menggunakan teorema faktor, (3) pada soal 3 merancang model matematika dan menyelesaikan permasalah yang diaplikasikan dalam kehiduan sehari-hari.

Studi lapangan yang telah dilakukan di MAN 1 Sleman dengan meminta satu orang guru bidang studi matematika yang mengajar di kelas XI dan 6 orang siswa perwakilan kelas XI untuk mengisi angket. Dari hasi studi lapangan, dapat diketahui bahwa 43,5\% dalam penyampaian materi, guru lebih dominan menggunakan metode ceramah dan diskusi. Sedangkan $27 \%$ guru yang menggunakan metode eksperimen. Fakta yang ada dilapangan, juga menunjukkan bahwa 99\% guru tidak menggunakan LKS saat proses pembelajaran. Akan tetapi guru menggunakan buku paket sebagai pengganti LKS berbasis kurikulum 2013 dalam kegiatan pembelajaran yang dipinjamkan oleh sekolah.

Berikut disajikan hasil analisis kevalidan oleh validasi dan subjek uji coba

Tabe3. Hasil Validasi

\begin{tabular}{rlll}
\hline No & Aspek yang dinilai & Presentase (\%) & Kategori \\
\hline 1. & Kesesuian isi & $80,7 \%$ & Sangat tinggi \\
2. & Keterbacaan & $83,2 \%$ & Sangat tinggi \\
& & $82,4 \%$ & Sangat tinggi
\end{tabular}

Hal ini ditunjukkan dari jawaban validator, dimana rata-rata validator menyatakan sangat setuju dan setuju dalam beragai pernyataan yang terdapat pada instrumen validasi terhadap aspek keterbacaan. Validator sangat setuju dengan ukuran dan huruf pada LKS sudah sesuai dan dapat dibaca dengan baik, warna pada LKS sudah serasi antara warna satu dengan yang lainnya. 
Kualitas gambar pada LKS terlihat jelas oleh pembaca. Perpaduan antara gambar, warna teks, pada LKS sudah serasi dan dapat dibaca dengan baik, tulisan yang digunakan pada LKS sudah serasi antara bentuk huruf, ukuran huruf dan warna teks dapat dibaca dengan baik oleh pembaca. Validator juga sangat setuju kalimat yang digunakan dalam LKS sangat efektif.

Validator setuju bahwa pada setiap kegiatan yang terdapat pada LKS menumbuhkan rasa ingin tahu siswa, sehingga memotivasi siswa untuk bertanya, kemudian dilanjutkan dengan langkah mencoba LKS yang dilakukan secara terbimbing dengan cara mengumpulkan informasi secara kreatif dan mandiri. Pada LKS juga sudah terdapat langkah-langkah yang dapat menuntun siswa untuk dapat memecahkan masalah yang mengarahkan siswa untuk berfikir secara kreatif sehingga siswa dapat mendapatkana pengetahuan secara keseluruhan dan utuh

Berdasarkan dari persentasi penilaian hasil validasi dapat dikategorikan sangat tinggi, sehinggadapat disimpulkan bahwa antara keterbacaan, konstruksi, dan kesesuain keterbacaan pada LKS berbasis saintifik sudah sangat baik dan layak untuk dalam kegiatan pembelajara

Tanggapan siswa yang dilihat adalah persentase keterbacaan dan kemenarikan LKS. Uji keterbacaan bertujuan untuk mengetahui tingkat keterbacaan LKS oleh siswa, sehingga tidak menimbulkan beberapa pernyataan tafsiran ganda. Uji kemenarikan bertujuan untuk mengetahui tingkat kemenarikan siswa terhadap LKS. Berdasarkan perhitungan yang telah dilakukan, persentase uji keterbacaan yaitu $86,3 \%$ dan uji kemenarikan yaitu $73,5 \%$. Pada uji keterbacaaan meenurut siswa yaitu 86,3\% yang termasuk sangat tinggi, sehingga dapat disimpulkan bahwa LKS dapat dibaca dengan baik dan tidak menimbulkan pernyataan tafsiran ganda, sehingga mempermudah siswa dalam mempelajari LKS.

Pada uji kemenarikan menurut siswa yaitu 73,5\% yang termasuk tinggi. Sehingga dapat disimpulkan bahwa LKS dapat dikatakan menarik dan tidak membosankan sehingga dapat meningkatkan minat belajar siswa. Akan tetapi ada beberapa dari responden yang memberikan pernyataan tidak setuju dari angket kemmenarikan. Maka dapat ditarik kesimpulan masih ada beberapa bagian yang harus diperbaiki guna mendapatkan LKS berbasis saintifik yang benarbenar sesuai. Adapun beberapa bagian yang perlu diperbaiki yaitu gambar yang kecil, serta bentuk tulisan yang monoton.

\section{SIMPULAN DAN SARAN}

Berdasaran hasil penenlian tersebut dapat disimpulkan yaitu 1) Telah dikembangkan LKS dengan pedekatan saintifik pada pokok bahasan polinom. 2) karakterisitik pada LKS 
dengan pendekatan saintifik pokok bahasan polinom yaitu: a) LKS disusun secara menarik dan sistematis, sehingga siswadapat meneyelesaikan dan mengaplikasikan konsep polinom pada kehidupan sehari-hari. b) Isi LKS disusun secara sistematis yang mengacu pada kompetensi inti (KI), kompetensi dasar (KD) dan indikator pencapaian (IPK). c) Bahasa yang digunakan sederhana dan komutatif. e) LKS disertai petunjuk penggunaan LKS, untuk membantu siswa dalam penggunaan LKS

Respon guru terhadap LKS yang dikembangkan yaitu aspek keterbacaan, kesesuian antar kompetensi dasar dengan indikator, serta pengembangan soal cerita yang diaplikasikan dalam kehidupan sehari-hari. Hal ini dapat dilihat dari persentase keterbacaan 83,2\%, konstruksi $82,4 \%$, dan kesesuain isi $80,7 \%$

Respon siswa terhadap LKS yang dikembangkan yakni dilihat dari keterbacaan dan kemenarikan LKS adalah baik. Hal ini dapat dilihat dari persentase keterbacaan yakni 86,3\% dan kemenaraikan yakni $73,5 \%$. Hal ini dapat ditarik kesimpulan yaitu bahwa hasil pengebangan LKS dengan pendekatan saintifik pokok bahan polinom sudah menarik serta dapat menimbulkan minat siswa dalam belajar.

\section{DAFTAR PUSTAKA}

Ardiani, R. N. 2014. Pengembangan Bahan Ajar Berbasis Masalah Melalui Metode Group Investigation Untuk Memfasilitasi Pemahaman Konsep Dan Kemampuan Pemecahan Masalah Matematika (Skripsi) Yogyakarta.

Arikunto, S. 1997. Penilaian Program Pendidikan. Edisi III. Jakarta: Bina Aksara

Bintari, N L G R P., Sudiana I N., \& Putrayasa I D. 2014. Pembelajaran Bahasa Indonesia Berdasarkan Pendekatan Saintifik (Problem Based Learning) sesuai Kurikulum 2013 di Kelas VII SMP Negeri 2 Amlapura. E-journal Program Pascasarjana Universitas Pendidikan Ganesha Program Studi Pendidikan Bahasa Indonesia, Vol. (3). Diakses dari

http://pasca.undiksha.ac.id/ejournal/index.php/jurnal_bahasa/article/viewFile/1185/92 4.

Risnawati. 2008. Strategi Pembelajaran Matematika. Pekanbaru: Suska Press. 